\title{
HIGHER EDUCATIONAL EMPOWERMENT, ITS IDEAL PARAMETERS AND THEIR CO- RELATION WITH ECONOMY
}

\author{
Mohit Satoskar ${ }^{1}$ and Anuprita Satoskar ${ }^{2}$ \\ ${ }^{1}$ Department of Computer Engineering, Ramrao Adik Institute Of Technology, \\ Navi Mumbai, India \\ mohitsatoskar@gmail. com \\ ${ }^{2}$ Department of Commerce, Mumbai University, Mumbai, India \\ satoskar.anuprita@gmail.com
}

\begin{abstract}
Co-relation between economy and post-graduation studies are highlighted. Bridging the gap between unemployment and post- graduates are essential in this competitive world. Detailed assessment shows human transition phases. The ideal factors to choose precise post-graduate career is analyzed. Problem related to unemployment is discussed briefly. It is shown how STEM related streams requires concealed professional mid -term work-experience in course structure.
\end{abstract}

\section{KEYWORDS}

Economy, Post-Graduation, Assessment, Unemployment, STEM, Work-Experience

\section{INTRODUCTION}

To foster and permeate better improved quality life, it is essential to alter change the higher educational structure which will produce successful professional and strengthen economy for betterment of society. In 2013-2014, in India, total vacant seats in Engineering/Technology were 4,62,580 [6]. Speaking about American Education, more than 36 million Americans- a fifth of the working age population, have gone off to college and left without a degree*. [4] However, there are several crucial factors such as tuition hike, lack of skills and opportunities. Non updated curriculum or course structure straight away impact on skilled jobs which further impacts on economy.

Higher educational institutions should deliver generic professionals with the excellence in education which will become pivotal 'ThinkTank' to industry. However, professional work experience in industry during studies will strengthen students ability and will try to boast their confidence level.

However, varsities should contribute industry oriented professional work experience as a top-up in course structure. Ultimately, the process will start from developing and highlighting David C. Wyld et al. (Eds) : NETCOM, NCS, WiMoNe, CSEIT, SPM - 2015

pp. 195-201, 2015. @ CS \& IT-CSCP 2015

DOI : $10.5121 / \mathrm{csit} .2015 .51616$ 
entrepreneurship skills. By 2025, two thirds of all jobs in United States will require education beyond high school*. [4]

\section{AIMS OF RESEARCH}

a) To design ideal course structure for STEM courses which will contain professional workexperience as a core module to sharpen practical abilities of students.

b) To analyze inter-dependency between economy and post graduation studies with human transition phases.

c) This study will provide generic solution which will act as 'ThinkTank' for students to choose specialization stream in higher education.

d) This should reduce the rate of unemployment in fresher's.

\section{OBJECTIVES}

i. This study can built up holistic growth and good employability under competitive market conditions.

ii. The main objective of this research is to improve economy constraints and produce successful professional.

\section{CO-RElation BETWEen ECONOMY AND POST-GRADUATION STUDIES}

The Average life span lived by an individual is grouped according to the decisions the choices that he has to make during that time span and are analyzed accordingly. The choices that the individual makes affects the rest of his life in various aspects. The following groups will clearly state about the importance of the various phases and the importance of the choices.

- Education (15-18): The decisions in this phases are concerned with the potential quality of the rest of the life of the concerned individual. The decisions are regarding the educational directions which later shape their futures.

- Professional Transition (25-30): This is the practical phase of the individuals life span where the person has to choose job. The working environment has to be in such a way where the best of the knowledge acquired in the previous stages can be implemented in the real life.

- The Thirties Assessment (30-35): This is the phase where the person has to think about various other factors as the social factor, or the financial factor, or the decisions regarding family and settlement are taken. The knowledge which he has acquired has to be given back to the society.

- The Forties Transition (35-45): During this time the person analyses the way of life he has lived. The disparity between the dreams and aims he had set for his life the position where he stands is realized by him. 
- Mid-age Assessment (45-55): The importance of life of meaning is realized by the individual. The consequences of the decisions and the choices made are to be faced.

- Pre-Retirement Transition (55-65): If the decisions taken in the earlier stages are of the right path they lead to the destination of satisfaction of achieving of the preset goals and aims. And if the decisions are in the any contradiction they lead to aimlessness and the search of the connecting a bridge between the ideal situation and the actual situation.

- The Seventies Transition (65-75): The phase of passing the knowledge to the next generations. The experiences and the consequences are passed to the next generation for their good.

- Seniority Transition (75-85): here the shifting process starts. the individual gradually shifts towards the phase of dependency from the various phases of independency.

\section{THE IDEAL AND REALiSTiC FACTORS To CHOOSE POST- GRADUATION AREAS}

Factors to be taken into consideration while choosing the path towards the profession of information technology stream are the initiative taken towards being a professional. Presently the factors that has to be considered and the factors which are considered in the reality deviate drastically. And the gap between the ideal factorial model and the present conditions has widened to bridge which concludes in the global problem of unemployment. Currently while choosing following factors are considered by the individual while opting for higher education in the field of information technology-

\subsection{Priorities}

The individual rather than thinking and considering the most vital factors while opting for this particular profession thinks of the priorities. The priorities such as the luxuries offered by this profession or even the illusion created by the industries about the stability of the profession and the life provided by it.

\subsection{Capacity}

Capacity of any person is of three types namely physical, emotional, and intellectual. If the person does not think of pushing his capacity as a professional he will not succeed. The capacity is the polished constraint. The capacity of the student is often misunderstood with the natural capabilities that e possess. And such misunderstanding affect the direction chosen by the student while choosing a post graduation program.

\subsection{Generalized Theory}

While choosing the direction towards being an professional in the field of information technology the students takes into consideration the most generalized factors which are into the minds of the society traditionally over a long period of time. While taking such things into consideration the student forgets the difference between the general constraints and his individual capabilities. 


\subsection{Financial Constraints}

In this fast paced modern era students while choosing the course for their post graduation level make this factor their priority. Rather than analyzing their own abilities and skills they possess naturally and those which they can develop over a period of time by practicing they are more concerned about the financial future that the field of the information technology has to offer and also the financial needs for opting that course.

\subsection{Market Analysis}

Market conditions is the most crucial external factor affecting the student's decisions. The job opportunities which are actually present for the post graduates and the illusion which depicts the opportunities affect the decision. If the illusion does not provide for a stable future and financial stability the student is hesitant about the career and if the illusion created by the industries suggest anything otherwise there arises the problem of overcrowding which ultimately leads to the problem of unemployment.

\subsection{Secondary Experiences}

Each graduate taking into consideration the future courses to pursue has to think about the risk factor that comes along. In this unstable and ever-changing era of modernization while turning towards any direction they take into account the experiences of the professionals already from that particular area. Such kind of information is the second hand or the secondary information. The main constraint of individuality is ignored when the decisions taken are based on such secondary information.

\section{IDEAL SITUATION CONSIDERATION}

The factors which are considered in reality and the factors that actually have to be considered deviate from each other. The factors of the deviation and the constraints that affect the deviation along with the consequences are discussed below:

\subsection{Capabilities}

Capabilities are nothing but the natural abilities and the gifts that the student possesses. A graduate opting for his post graduation in the profession of information technology has to have certain natural abilities. These natural abilities are the natural gifts and not the ones which the person can develop over the period of time. The most crucial ability that a information technology professional has to possess is the logicality. He has to be very strong in logics and solving the problems with these logics.

\subsection{Skills}

Skill is the ability which is polished over a period of time with rigorous and continuous practice. The professional from the field of technology has to polish various skills as his communication, the skills of analyzing a particular problem, the skill of providing the most optimal solution, skills of taking the right decisions for the satisfaction of the particular problem in the optimum time period. 


\subsection{Interests}

Interest can be aptly stated as the creative energy that motivates the professional to do the particular thing and take certain decisions. The technology professional must be passionate about the technology, the advancements, and the various other factors that constitutes the technology. He can develop his particular interest areas by opting for the corresponding course areas while choosing a course structure while pursuing his post graduation education.

\subsection{Goals}

Goals are nothing but the ambitions of the person. In the stream of technology the ambitions is the most primary factor which is supported along with the other factors for being successful in that particular field. Pre determined goals only help one to decide the path to achieve those. Accomplishment of such goals provides the industries with the accomplished information technology professionals.

\subsection{Principals and Personality}

While taking an decision of striving towards the profession of the information technology the factors of the personality and the principles of the individual even has to be considered. The student has to be constantly aware of the advancement of this fast paced ever-changing world of the technology. To keep the pace along with the quick and ever changing market conditions he has to be a decision taker and a risk bearer. Such qualities will help in accomplishing his preset goals and being a successful individual.

\subsection{Combination of Goals and Reality}

The preset goals and the ways to achieve these goals along with the real time constraints affect the quality of the professional that is produced by the industry of technology. Not only the goals but the complimentary course structure, the exposure to the post graduate student will develop his knowledge making him ready to face the real time challenges in the working environment and providing the most correct logical solution in the optimum time and resources.

\section{PROBLEM OF UNEMPLOYMENT}

Because of the various factors discussed above the problem of unemployment arises which can be stated and explained as follows* [2]:

$$
(\mathrm{ISC}-R S C)+(I C S-R C S)+\text { Other }=\text { Unemployment }
$$

ISC $=$ Ideal situation considerations; $\mathrm{RSC}=$ Real situation considerations; ICS $=$ Ideal course structure; RCS= Real existing course structure; Other= Other variables; Unemployment= Problem of unemployment;

In the above stated mathematical representation it is stated that the deviation between the ideal situation considerations and the real situation considerations, along with the difference between the ideal course structure and the real existent course structure if combined with various other variables namely the market expectations and conditions or the economies constitute a crucial global problem of unemployment. These all deviations created a huge gap between the industry 
expectations and the requirements and the quality of the knowledge that the student actually possess which is hard to bridge.

\section{Successful Professional}

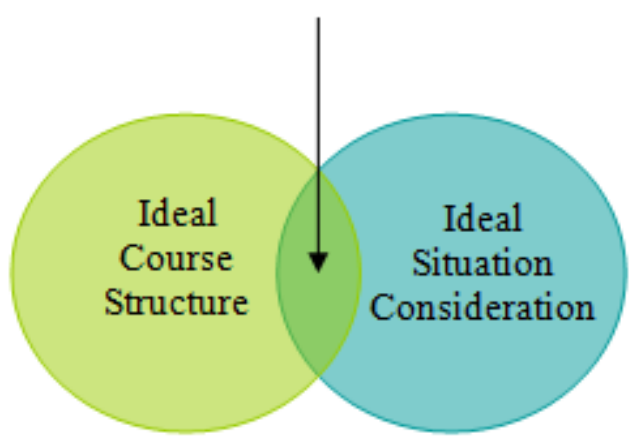

Figure 1 Ideal Strategy for Successful Professional

when the individual is furnished with an ideal course structure where he has considered ideal situation considerations, along with many other dependant variables males a successful professional. Ideal course structure will enhance his abilities as a professional the abilities which he had taken into account while choosing that respective field. And when a successful professional will work in the real time environment his efficiency will not only benefit the organization he is working for but also the economy of the particular nation. This model which proposes the ideal strategy will help us solve many economical issues such as unemployment, poverty, overcrowding and many more.

\section{CONCLUSION}

Providing a solution to the problem of unemployment through providing a better course structure to the pupils which will enhance their skills and strengthen their abilities to work in the competitive environment efficiently. Also it takes into consideration various ideal factors while opting for that particular field and striving towards success.

However, the outcome will be more realistic for the employer as well which will help to reduce the unemployment rate in developing countries.

\section{ACKNOWLEDGEMENTS}

Authors would like to convey sincere gratitude to Hon'ble Anant Tibile (Eminent Indian Novel Writer).

\section{REFERENCES}

[1] "General Economics", The Institute of Chartered Accounts of India. New Delhi. ISBN: 978-81-8441$035-8$

[2] Satoskar, Mohit, Satoskar, Anuprita. " Strategic Model of Creative Higher Education to Employment for Information Technology". Proceedings of The World Congress on Engineering and Computer Science 2015. San Francisco. U.S.A. pp 320-324. Vol 1. ISBN: 978-988-19253-6-7. 
[3] Mohit Satoskar, "Cognitive Prior-Knowledge Testing Method for Core Development of Higher Education of Computing in Academia", FECS'15- The 2015 Int'l Conference on Frontiers in Education: Computer Science and Computer Engineering, Las Vegas, July 2015. Paper ID: FEC6191.

[4] http://www.gatesnotes.com/Education/11-Million-College-Gradss (accessed: 15 November 2015)

[5] "World Education Report", 2000, United Nations Educational, Scientific and Cultural Organization.

[6] http://www.aicte-india.org/downloads/parliment_questions/PQ_Supplementary_362.pdf (accessed: 20 November 2015)

[7] http://www.uis.unesco.org/FactSheets/Pages/Literacy.aspx

[8] Report on Adult and Youth Literacy, 1990-2015, UNESCO. Canada. ISBN: 978-92-9189-117-7

[9] Satoskar ${ }^{1}$, Mohit and S. Mali. "Comprehensive Curriculum of Programming for Engineers, its Teaching Models and in-Lab Monitoring Technique", Proceedings of the International MultiConference of Engineers and Computer Scientists. Vol. 1. 2015. ISBN: 978-988-192530209

\section{AUTHORS}

Mohit Satoskar received Bachelors of Engineering (Hons) degree in Computer Systems Engineering from London Metropolitan University, United Kingdom in 2012. Currently, Mohit is a Research Associate with Department of Computer Engineering in Ramrao Adik Institute of Technology, Navi Mumbai. India. Mohit has published several research papers, see the latest http:// independent.academia.edu/ MohitSatoskar/Activity. He did consulting for ECHS-Indian Armed Forces. He is a Certified Ethical Hacker. Mohit's current research interests are: natural multilanguage processing, educational technology, e-governance, management information systems, curriculum design and implementation.

Anuprita Satoskar is a student of Institute of Chartered Accountants of India. She is also with University of Mumbai pursuing Bachelor of Commerce. Anuprita is a National Award Winner of TATA Building India competition.
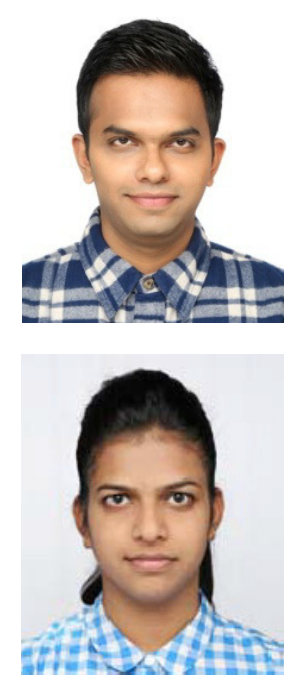